\title{
Awareness of Ecological Economics as a Model for Promoting Sustainable Construction
}

\author{
Ayodeji Oke, *Clinton Aigbavboa \& Mpho Ndou \\ University of Johannesburg, Johannesburg, South Africa \\ emayok@gmail.com, *caigbavboa@uj.ac.za, jrndou@gmail.com
}

\begin{abstract}
Construction industry is a major consumer of natural resources and this has a significant impact on the environment and socio-economic development of society. The result of this impact includes deforestation; climate change, air, water and land pollution; and the like. Ecological economics (EE) models are tools for assessing and understanding these issues with a view to enhancing green buildings and sustainable construction in general. As part of a continuous study, this research therefore examines the level of awareness of the concept of EE by construction professionals in a quest to adopting the principle of sustainable development. Data were collected through questionnaires administered on relevant and experienced construction professionals such as construction project managers, architects, engineers, quantity surveyors and construction managers. EE as an aid would help in mitigating construction impacts on the environment, thereby enhancing sustainability but it is barely practised in the construction industry. This is as a result of the fact that construction professionals have little or no knowledge of its existence in the local industry. Most professionals with knowledge of the concept in the study area obtained the information on sustainability through the media and short courses .. The basic influencing factors are related to professionals' levels of education, the economic development of the country and knowledge of the environment. Introducing EE through communicating new ideas to stakeholders (through environmental campaigns, conferences, and the like) as well as incentivising ideas for change relating to greener construction will assist in overcoming the barriers to the adoption of EE in the construction industry. Professionals also need to keep abreast of current sustainable practices, their benefits, challenges, barriers as well as the methods of overcoming these barriers in their quest for delivering sustainable projects.
\end{abstract}

Keywords: Community empowerment; Ecosystem; Sustainable neighbourhood

\section{Introduction}

For many decades construction professionals worldwide have struggled with keeping to the stipulated construction project budgets, time frames and quality requirements of their projects. This occurs mainly as a result of the inadequate or improper planning of the projects by the selected professional teams. Hussin, Rahman and Memon (2013) observed that the built environment has a high number of inhospitable construction activities owing to the large quantities of natural resources being consumed. This results in the pollution of the environment, thus negatively impacting on the environment. It was further identified that the majority of construction professionals were not too enthusiastic about environmental conservation within the construction industry. Kolev (2009) highlighted that the carbon emissions from buildings supplemented the rapidly increasing global warming and extensive weather variations globally. One of the methods of understanding this is ecological economics which is concerned with the study of the environment, the impact of various activities and the means of minimising them. Through mitigation of the environmental impact of the construction industry, EE can promote sustainable development. This will be achieved by improving the quality of human life on one the hand and on the other, maintaining the magnitude of the ecosystem locally and globally which the present sustainable model fails to do. As a result, Dodds (1997) concluded that the contribution of EE in aiding sustainability has emphasised maintaining an active stream of goods and services that currently impact the well-being of the environment at large. There is therefore a need to incorporate the general sustainable development concepts into conventional construction practices through EE as a model. As part of on-going research, this article examines the level of awareness and knowledge of various construction professionals regarding the concept of ecological economics in the quest to promote its adoption for the delivery of sustainable projects in the construction industry.

\section{Literature Review}

Awareness of Ecological Economics Concept: The construction industry consists of various indispensable professionals working together for the purpose of delivering projects to acceptable standard. According to 
Elforgani and Rahmat (2010), it was noted that due to the materials and energy efficiency choice, design team members, especially architects and engineers, influence the delivery and production of sustainable construction. It was further revealed that the fruition of green building is influenced by the participation of other industry players. Buys and Hurbisson (2011) argued that despite contractors being key players in green construction, as a result of their being part of the project delivery system and contract specifications, contractors still had limited involvement in the design process. Furthermore, it was noted that contractors' participation in sustainable construction through recycling and reusing of material waste, limitation of hazardous material being used and the use of efficient production systems was important but not sufficient. However, Windapo and Cattell (2013) discovered that the use of integrated procurement systems (IPC) such as design and build, turnkey, and procure and construct could warrant that contractors could be more actively involved in the design and construction of sustainable development. Environmental awareness is defined by Kollmuss and Agteman (2002) as the knowledge of how human behaviour impacts the surrounding environment. Zsóka (2005) highlighted that five constituents of ecological awareness based on critical research conducted are ecological knowledge, environmental attitudes, environmental values, willingness to act, and actual behaviour. Nevertheless, Chawla (1999) discovered that an increase in $\mathrm{n}$ ecological awareness does not necessarily lead to pro-environmental behaviour. Various studies indicate the gap that exists between the constituents of ecological awareness that is caused by the diverse nature of reality and economic-structural factors.

Fuchs and Lorek (2005) stated that switching from an efficiency-based model to a sustainable approach requires significant alterations in the manner of conduct. Professionals with an escalated level of ecological awareness may not act sustainably owing to socio-economic factors, thus leading to a constant battle between personal values and societal expectations (Sears, Freedman and Peplau, 1985; Szerényi, Zsóka and Széchy, 2011). According to Balderjahn (1988), ecologically-concerned professionals belong mainly to wealthier construction companies. However, the financial enrichment of the construction industry will not reduce the burden on the environment. Sanne (2002) observed that professionals are captive to unsustainable lifestyles by circumstances such as social norms, regardless of their willingness to act in that manner. Furthermore, it was stated that circumstances developed as a result of other interests, and the adoption of sustainable approaches is limited owing to policies that look into minimum means over a greater field. This prevents the adaptation of $\mathrm{EE}$ as a sustainable model in the construction industry.

Construction professionals act according to their discretion rather than the on basis of the scientific definition of sustainable consumption (Csutora, 2012). The awareness-behaviour gap in various industries has been exhaustively investigated by numerous studies. Kollmuss and Agteman (2002) discovered that demographic factors, internal factors (motivation, professionals' environmental knowledge, awareness, priorities, and responsibilities) as well as external factors (institutional, economic, social, and cultural), are vital influencing factors of pro-environmental behaviour. In an interview conducted by Chawla (1999), it was revealed that childhood experiences of professionals are the most important factor affecting the behaviour of various environmentalists in the USA and Norway. It was further highlighted that education is the least important variable. Similarly, Jackson (2005) argued that changing professionals' behaviours is currently challenging because individual behaviours affects the state of affairs of the industry at large. Also, Hobson (2001) supported this view by mentioning that at times, ecological awareness campaigns are not effective enough in promoting the industry's promotion of sustainable construction.

\section{Methodology}

A survey design was adopted for the collection of data for this study. The population includes architects, quantity surveyors, engineers, construction project managers, construction managers and other relevant professionals within the built environment in South African construction industry, specifically in the Gauteng region. The research adopted the use of a close-ended questionnaire based on data obtained from a literature review of existimg materials in the area of sustainability, ecology and economics. The questionnaire was designed to explore the awareness level of ecological construction based on various demographic, internal and external factors highlighted from literature. Using convenience sampling, the distribution of questionnaires to respondents was mainly through electronic mail as well as hand delivery and they were retrieved through the same means. Prior to actual distribution, a pilot study was carried out among selected 
academics and construction professionals to test and improve the instrument. Their comments, observations and views were examined and considered in the preparation of the final instrument for data collection.

The first section of the questionnaire examined the background of the respondents while the second portion explored the awareness levels of EE amongst identified construction professionals. The importance of the identified variables was examined based on the level of agreement of respondents using a five-point Likert scale. The ratings were as follows: $1=$ Strongly disagree; $2=$ Disagree; $3=$ Neutral; $4=$ Agree; $5=$ Strongly agree. Mean item scores (MIS) and standard deviations (SD) were thereafter computed for each of the variables and the values were used in ranking and determining their importance. Cronbach's alpha test was carried out on the group of collected data and values of 0.701 and 0.714 were obtained for responses in respect of sources of information and reasons for the gap in knowledge. This is acceptable as noted by George and Mallery (2003) as well as Punch (2005), namely that the value of the Cronbach's alpha above 0.7 is acceptable.

\section{Results and Discussion}

Biographical information of respondents: Finding revealed that 38 per cent of the respondents are engaged in contracting firms, 40 per cent worked for consulting firms, 4 per cent worked for developers, 14 per cent worked for project management firms and 4 were employed in other fields, which included tertiary institutions and commercial banks. Further results showed that 52.08 per cent of the respondents' companies work for the private sector, 12.50 per cent work in the public sector and 35.42 companies operate in both the private and public sectors. Findings relating to respondents' current position in the company showed that 8 per cent are architects, 40 per cent are quantity surveyors, and 12 per cent are engineers. Also, 14 per cent are project managers, 8 per cent are construction managers or site engineer/agent, 14 per cent are construction project managers, and 4 per cent held other positions, which included a facility manager.

Sources of ecological economics knowledge: Table 1 reveals the respondents' rankings of the main sources of information of obtaining knowledge on sustainable construction in the study area. It reveals that short courses in environment and sustainability are the most important with a mean item score (MIS) of 3.96 and a standard deviation (SD) of 0.989 . This is followed by the media and articles, attending seminars arranged by the government, and personal research. Other means are through professional councils and discussions as well as information from co-workers.

Table 1: Source of information on ecological economics

\begin{tabular}{llll}
\hline Sources & SD & MIS & Rank \\
\hline Short courses in environment and sustainability & 0.99 & 3.96 & 1 \\
Media/Articles & 0.96 & 3.82 & 2 \\
Attending seminars arranged by the state & 1.11 & 3.80 & 3 \\
Personal research & 0.84 & 3.70 & 4 \\
Professional councils & 0.84 & 3.70 & 5 \\
Co-workers & 1.01 & 3.38 & 6 \\
\hline
\end{tabular}

$\mathrm{SD}=$ Standard deviation; MIS = Mean item scores

Influences of ecological economics knowledge gap: Causes of the gap in knowledge relating to ecological economics amongst professionals are indicated in table 2. It reveals that the level of education is the most important demographical factor, followed by sector of employment and childhood experiences. In addition, economic development is the most significant external factor with an MIS of 3.88 and an SD of 0.558, followed by social and cultural aspects, institutional factors and increased competitiveness on project bids.

Moreover, the table further reveals environmental knowledge as the most important internal factor with MIS of 3.88 and SD of 1.023; lack of motivation was ranked second with an MIS of 3.78 and SD of 0.790 ; environmental awareness was ranked third with an MIS of 3.66 and SD of 0.848; values (individual and organisational) was ranked fourth with an MIS of 3.70 and SD of 0.848 , while work priorities and responsibilities were ranked fifth with an MIS of 3.58 and SD of 0.835 . 
Table 2: Causes of gap in EE knowledge

\begin{tabular}{lllll}
\hline Factors & SD & MIS & $\begin{array}{l}\text { Rank } \\
\text { Group }\end{array}$ & Overall \\
\hline $\begin{array}{l}\text { Demographic factors } \\
\text { Level of education }\end{array}$ & 0.96 & 3.88 & 1 & 2 \\
Sector of Employment & 1.07 & 3.52 & 2 & 11 \\
Childhood experiences in nature & 1.14 & 2.92 & 3 & 12 \\
External factors & & & & \\
Economic development & 0.56 & 3.88 & 1 & 1 \\
Social and cultural aspects & 0.86 & 3.72 & 2 & 5 \\
Institution & 0.79 & 3.70 & 3 & 7 \\
Increased competitiveness on project bids & 1.03 & 3.62 & 4 & 9 \\
Internal factors & & & & \\
Environmental knowledge & 1.02 & 3.88 & 1 & 3 \\
Lack of motivation & 0.79 & 3.78 & 2 & 4 \\
Environmental awareness & 0.97 & 3.70 & 3 & 6 \\
Values (individual and organisational) & 0.85 & 3.66 & 4 & 8 \\
Work priorities and responsibilities & 0.84 & 3.58 & 5 & 10 \\
\hline
\end{tabular}

$\mathrm{SD}=$ Standard deviation; MIS = Mean item scores

Discussion of findings: These findings on causes of knowledge gap of ecological economics were comparable with the findings by Kollmuss and Agteman (2002), where democratic factors such as the level of education and sector of employment were indicated as the most significant reasons for gaps in knowledge; external factors such as environmental knowledge and environmental awareness were also important factors behind the reason for the knowledge gaps of professional. Likewise, the findings were also similar to the those of the study done by Galli et al. (2014), revealing that the level of education as well as institutional factors affect the awareness levels of professionals regarding pro-environmental knowledge. However, , the finding in the current study were not in agreement with a survey conducted by Chawla (1999) who discovered that childhood experiences in nature were the most frequently mentioned and education was the least frequently mentioned factor during interviews with numerous professional environmentalist in the USA and Norway. This is also similar to the findings of Csutora (2012) and Balderjahn (1988). Csutora (2012) advocated that ecologically concerned professionals belong mainly to wealthier construction companies. From the current study, it was discovered that 62 per cent of the respondents' companies operated in the private sector, yet 62 per cent of the respondents had not been involved in a single 'green' or sustainable project.

\section{Conclusion and Recommendations}

The possibility for the adoption of ecological economics for delivery and production of sustainable of development is the overall goal of this study. Therefore, , this study evaluates the ecological and environmental awareness of professionals within the built environment with respect to their sources of information and factors influencing the gap in knowledge. Findings revealed that there is low awareness of ecological economics and the basic concept of sustainable development among construction professionals in the study area. This is due mainly to various demographic, internal and external factors. The major ones are related to the education level of the professionals, their level of economic development and their knowledge of the environment. There is also a lack of information regarding the concepts. It is therefore recommended that all professionals in the construction industry should be educated and trained in the implementation of EE as a model for promoting sustainable construction. They should also keep abreast of trends and the various principles necessary for improving ecological economics awareness for the purpose of improving the performance of construction projects. Regulatory bodies and government agencies concerned with 
construction project performance and the delivery of sustainable infrastructure should therefore increase their level of sensitisation on the need for adopting and implementing the concept in the construction industry. In continuation of this work, further studies can be conducted into drivers, challenges and perceived benefits of ecological economics if fully adopted in the construction industry.

\section{References}

Balderjahn, I. (1988). Personality variables and environmental attitudes as predictors of ecologically responsible consumption patterns. Journal of Business Research, 17, 51-56.

Buys, F. \& Hurbissoon, R. (2011) Green buildings: A Mauritian built environment stakeholders' perspective. Acta Structural, 18, 81-101.

Chawla, L. (1999). Life paths into effective environmental action. The Journal of Environmental Education, $31(1), 15-26$.

Csutora, M. (2012). One more awareness gap? The behaviour-impact gap problem. Journal of Consumer Policy, 35(1), 145-163.

Dodds, S. (1997). Towards a 'science of sustainability': Improving the way ecological economics understands human well-being. Ecological Economics, 23(2), 95-111.

Elforgani, M. S. \& Rahmat, I. (2010). An investigation of factors influencing design team attributes in green buildings. American Journal of Applied Science, 7(7), 976-986

Fuchs, D. A. \& Lorek, S. (2005). Sustainable consumption governance: A history of promises and failures. Journal of Consumer Policy, 28, 261-288.

Galli, A., Wackernagel, M., Iha, K. \& Lazarus, E. (2014). Ecological footprint: Implications for biodiversity. Biological Conservation, 173, 121-132.

George, D. \& Mallery, P. (2003). SPSS for Windows step by step. A simple guide and reference. 11.0 update, $4^{\text {th }}$ ed., Boston: Allyn and Bacon.

Hobson, K. (2001). Sustainable lifestyles: Rethinking barriers and behaviour change. In M. J. Cohen \& J. Murphy (Eds.), Exploring sustainable consumption: Environmental policy and the social sciences. Pergamon, Amsterdam, pp.191 208.

Hussin, J. M., Rahman, I. A. \& Memon, A. H. (2013). The way forward in sustainable construction: issues and challenges. International Journal of Advances in Applied Sciences, 2(1), 15-24.

Jackson, T. (2005). Motivating sustainable consumption: A review of evidence on consumer behaviour and behavioural change. Energy \& Environment, 15, 1027-1051

Kolev, M. (2009). Eco-building and job creation. Green building handbook for South Africa. CSIR Built Environment, Pretoria, South Africa.

Kollmuss, A. \& Agteman, J. (2002). Mind the gap: Why do people act environmentally and what are the barriers to pro-environmental behaviour? Environmental Education Research, 8, 239-260.

Punch, K. F. (2005). Introduction to social research: Quantitative and qualitative approaches. $2^{\text {nd }}$ ed., California: Sage Thousand Oaks.

Sanne, C. (2002). Willing consumers - or locked-in? Policies for a sustainable consumption. Ecological Economics, 42, 273-287.

Sears, D. O., Freedman, J. L. \& Peplau, L. A. (1985). Social psychology. Prentice Hall, Englewood Cliffs, New Jersey.

Szerényi, Z. M., Zsóka, Á. \& Széchy, A. (2011). Consumer behaviour and lifestyle patterns of Hungarian students with regard to environmental awareness. Society and Economy, 33(1), 89-110.

Windapo, A. O. \& Cattell, K. (2013). The South African construction industry: Perceptions of key challenges facing its performance, development and growth. Journal of Construction in Developing Countries, 18(2), 65-79.

Zsóka, Á. (2005). Consistency and awareness gaps in pro-environmental organisational behaviour. Thesis (PhD). Corvinus University of Budapest. 